\title{
Erratum to: Effectiveness of the ICare rebound tonometer in patients with overestimated intraocular pressure due to tight orbit syndrome
}

You Kyung Lee $\cdot$ Ji Young Lee $\cdot$

Jung Il Moon $\cdot$ Myoung Hee Park

Published online: 22 October 2014

(C) Japanese Ophthalmological Society 2014

Erratum to: Jpn J Ophthalmol

DOI 10.1007/s10384-014-0343-3

As the result of a change that had occurred during editorial processing, the authors' given names appeared with only initials, not full names, in the article. The correct full names are shown above. The publisher sincerely apologizes for the error.

The online version of the original article can be found under doi:10.1007/s10384-014-0343-3.

Y. K. Lee · J. Y. Lee · J. I. Moon · M. H. Park ( $ه)$

Department of Ophthalmology, Yeouido St. Mary's Hospital, College of Medicine, The Catholic University of Korea, \#62

Yeouido-dong, Yeoungdeungpo-gu, Seoul 150-713, Korea

e-mail: marypark@catholic.ac.kr

Present Address:

Y. K. Lee

Medical and Scientific Affairs, Allergan Korea, Seoul, Korea 